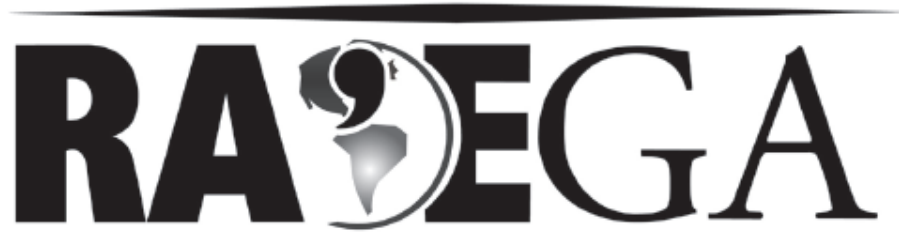

O ESPAÇO GEOGRÁFICO EM ANÁLISE

\title{
POTENCIAL DE USO AGRÍCOLA E LEGISLAÇÃO AMBIENTAL VOLTADOS AO PLANEJAMENTO NA BACIA DO RIO PEQUENO-PR ${ }^{1}$
}

\section{Potential for agricultural use and environmental law to the planning of Pequeno watershed, Brazil}

\author{
Marcia Regina Gomes de Jesus SOARES ${ }^{2}$ \\ Jorge Luiz Moretti de SOUZA ${ }^{3}$ \\ Daniela JERSZURKI ${ }^{4}$
}

\section{RESUMO}

O presente trabalho teve por objetivo elaborar para a bacia do Rio Pequeno, situada no município de São José dos Pinhais - PR, subsídios às diretrizes básicas de ação ambiental sustentável. O estudo foi baseado em análises das condições de uso atual em contraste com as características naturais do meio físico e do cruzamento desses dados com as limitações impostas pela legislação ambiental e, que associados às geotecnologias, proporcionaram como resultados a elaboração das cartas de Aptidão Agrícola das Terras e Conflitos do Uso e Ocupação Atual. Verificou-se que é necessário recuperar $41 \%$ da área para atender a legislação ambiental, $59 \%$ da área foi

\footnotetext{
${ }^{1}$ Parte de Dissertação de Mestrado da primeira autora, apresentada ao Programa de Pós-Graduação em Ciência do Solo, do Departamento de Solos e Engenharia Agrícola/SCA/UFPR

${ }^{2}$ Geógrafa, Mestre em Ciência do Solo. Professora na Universidade Tuiuti do Paraná, Curitiba, PR marcia.jesus@utp.br

${ }^{3}$ Engenheiro Agrícola, Doutor em Irrigação e Drenagem, Professor do Departamento de Solos e Engenharia Agrícola, Setor de Ciências Agrárias, Universidade Federal do Paraná. - jmoretti@ufpr.br

${ }^{4}$ Engenheira Agrônoma, Universidade Federal do Paraná - dani jerszurki@hotmail.com
} 
classificada como apta para a agricultura, devendo ocorrer preservação em $36 \%$ da área e, o uso adequado do solo obteve $59 \%$ de representatividade.

Palavras-chave: Hidrografia, aptidão agrícola, planejamento ambiental.

\section{ABSTRACT}

This study aimed to prepare for the Pequeno wathershed, located in the city of São José dos Pinhais - PR, subsidies for basic guidelines for sustainable environmental action. The study was based on analysis of current conditions of use in contrast to the natural characteristics of the physical environment and the crossing of these data with the constraints imposed by environmental legislation and, linked to geotechnology, provided results such as drafting letters of Aptitude Agricultural Lands and conflicts of use and occupancy Current. it is necessary to recover $41 \%$ of the area to meet environmental legislation, the system of agricultural suitability $59 \%$ of the area classified as suitable for agriculture, conservation should occur in $36 \%$ of the area and the proper use of soil obtained $59 \%$ of representativeness.

Key words: Hydrography, agricultural suitability, environmental planning.

\section{INTRODUÇÃO}

A Região Metropolitana de Curitiba (RMC) concentrará porções cada vez mais expressivas da população estadual, promovendo o incremento da demanda por alimento, o que resulta no uso intensivo do solo devido ao potencial aumento da produção agrícola (SOARES et al., 2008). Desta forma, torna-se urgente o planejamento físico territorial da região, avaliando não somente $\mathrm{o}$ aspecto econômico, mas também $\mathrm{O}$ ambiental, levando-se em consideração a fragilidade das áreas com intervenções antrópicas (DONHA et al., 2006).

A escolha de uma bacia hidrográfica como unidade de estudo em uma pesquisa, possibilita a análise e interpretação das alterações físicas ambientais, servindo de base para o planejamento e zoneamento da área (CHUEH, 2004). Possibilita também, o levantamento de áreas críticas com vistas à conservação e produção da água (PINTO et al., 2005) e como ferramenta básica para a conservação e preservação do ambiente (FIORIO et al., 1999). 
E com este intuito, a bacia hidrográfica do Rio Pequeno foi escolhida para ser utilizada no presente trabalho, por ser considerada o meio de integração dos componentes naturais e humanos, além de ser um importante instrumento de gestão na medida em que estabelece restrições e potencialidades com enfoque na RMC (WEBER et al., 1998). Além disso, o Rio Pequeno, afluente da bacia do Altíssimo Iguaçu, apresenta grande potencial de oferta de água, sendo responsável por grande parte do abastecimento público de água tratada de Curitiba e região metropolitana (ANDREOLI et al., 2000).

$O$ presente estudo teve por objetivo elaborar subsídios às diretrizes básicas de ação ambiental sustentável para a bacia do rio Pequeno, fundamentando-se nas análises das condições de uso e ocupação atual em contraste com características naturais do meio físico (em especial do solo, vegetação, topografia e hidrografia); e do cruzamento desses dados com as limitações legais impostas pela legislação que define a localização de áreas de proteção ambiental.

\section{MATERIAL E MÉTODOS}

A área de estudo do presente trabalho compreende a bacia do rio Pequeno, que está localizada no município de São José dos Pinhais, Paraná, com área aproximada de $128 \mathrm{~km}^{2}$, ocupando $14 \%$ da área total do município (Figura 1). A bacia hidrográfica do Rio Pequeno pertence à bacia hidrográfica do Altíssimo Iguaçu e tem suas nascentes atravessando o norte do município de São José dos Pinhais e sudeste de Curitiba, Estado do Paraná. A orientação principal da drenagem se dá no sentido leste-oeste. Em sua porção sudoeste, próxima a sede do município de São José dos Pinhais, apresenta um dos principais focos de expansão urbana da RMC (BRISKI et al., 2004). 


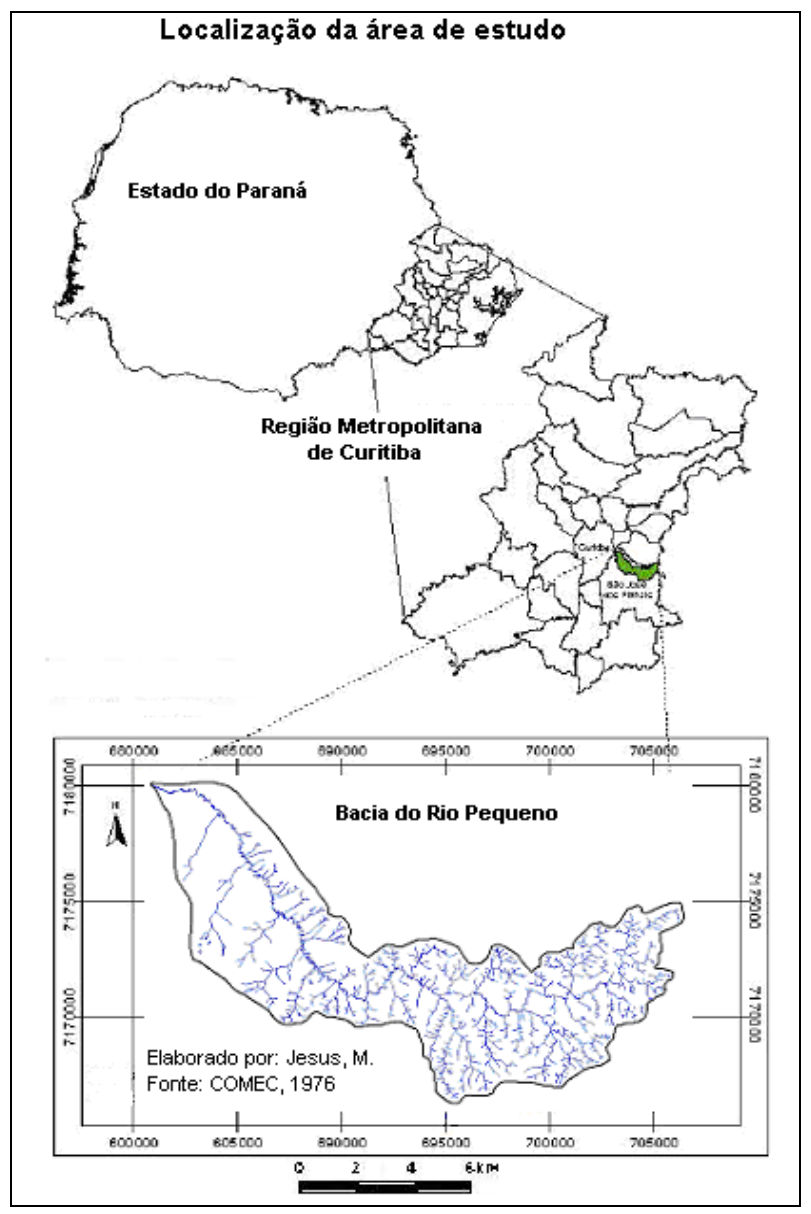

Figura 1 - MAPA DO MUNICÍPIO DE SÃO JOSÉ DOS PINHAIS, PARANÁ, CONTENDO A LOCALIZAÇÃO DA BACIA HIDROGRÁFICA DO RIO PEQUENO.

De acordo com classificação da Embrapa (1984), as classes e proporções dos solos encontrados na bacia do rio Pequeno são: (a) C Cambissolo (17\%); (b) LVA - Latossolo Vermelho-amarelo (23\%); (c) PVA Argissolo Vermelho-amarelo (27\%); (d) O - Organossolo (32\%); e, (e) L Neossolo Litólico (1\%). Os solos foram classificados de acordo com Embrapa (1999) a partir de levantamento de campo. A Carta de Solos foi digitalizada utilizando o software AutoCad 2002 (versão 15.3) e mesa digitalizadora, adaptado à escala 1:50.000, tendo como resultado a apresentação das classes pedológicas. A vegetação da região é caracterizada por Floresta Ombrófila Densa, Floresta Ombrófila Mista e Campo (IBGE, 1992). Segundo a classificação de Köppen, o clima do Município de São José dos Pinhais classifica-se como Cfb. 
A base de dados cartográficos foi constituída a partir de mapas digitais do levantamento planialtimétrico elaborados pela Comec (1976) e georreferenciados com um GPS. Os mapas de solos, declividade, aptidão agrícola, legislação ambiental e conflitos de uso, foram gerados em formato digital utilizando-se um software de Sistema de Informação Geográfica (SIG) denominado SPRING.

Para caracterizar o potencial de uso da bacia do rio Pequeno, utilizou-se a metodologia de aptidão agrícola de Ramalho Filho e Beek (1994), baseandose: (a) em dados de declividade e solo (Tabelas 1 e 2); e, (b) na caracterização das áreas protegidas por lei ou áreas de preservação permanente (APP). Em acordo com os critérios estabelecidos na legislação, as áreas protegidas foram mapeadas seguindo metodologia específica para cada uma das classes descritas na Resolução Conama 303/2002 (BRASIL, 2002a; BRASIL, 2002b). Esta resolução recomenda a preservação da vegetação do entorno dos rios e nascentes, sendo que as classes de aptidão agrícola das terras devem ser acrescidas das áreas de preservação permanente, correspondentes à classe 6 , destinada à preservação ambiental. O procedimento para a determinação consistiu na sobreposição do plano de informação contendo as APPs ao plano de informação de aptidão agrícola das terras.

TABELA 1 - SIMBOLOGIA CORRESPONDENTE ÀS CLASSES DE APTIDÃO AGRÍCOLA DAS TERRAS SEGUNDO RAMALHO FILHO E BEEK (1994).

\begin{tabular}{|c|c|c|c|c|c|c|}
\hline \multirow{3}{*}{$\begin{array}{l}\text { Classe de } \\
\text { aptidão } \\
\text { agrícola }\end{array}$} & \multirow{2}{*}{\multicolumn{3}{|c|}{ Lavoura }} & \multirow{2}{*}{\multicolumn{2}{|c|}{$\begin{array}{l}---- \text { Tipo de utilização ----- } \\
\text { Pastagem Silvicultura } \\
\text { plantada }\end{array}$}} & \multirow{3}{*}{$\begin{array}{c}\text { Pastagem } \\
\text { natural }\end{array}$} \\
\hline & & & & & & \\
\hline & A & B & C & B & B & \\
\hline Boa & $A$ & $\mathrm{~B}$ & $\mathrm{C}$ & $P$ & $\mathrm{~S}$ & $\mathrm{~N}$ \\
\hline Regular & $A$ & $\mathrm{~b}$ & $\mathrm{c}$ & $p$ & $S$ & $\mathrm{~N}$ \\
\hline Restrita & (a) & (b) & (c) & (p) & (s) & $(n)$ \\
\hline
\end{tabular}

Para a elaboração da carta de uso e cobertura do solo foi realizada a classificação supervisionada, ferramenta do software SPRING, realizada sobre as imagens de satélite dos anos de 2000 e 2006. Os temas obtidos nas cartas de uso e cobertura do solo foram: agricultura, área urbana, água/banhado 
(várzea), florestas/áreas seminaturais, silvicultura, campo e/ou pastagem e solo exposto.

As terras foram posicionadas dentro de seis grupos, em função da viabilidade de melhoramento de quatro das cinco qualidades básicas apresentadas na metodologia, sendo: excesso de água, deficiência de água, susceptibilidade à erosão e impedimentos à mecanização. A fertilidade natural não foi levada em consideração neste estudo, tendo em vista que os dados dispostos pela Embrapa foram insuficientes ao nível de especificidade da bacia do rio Pequeno.

A metodologia foi adaptada em relação ao fatiamento das classes de declividades (d), sendo: (a) $0<d \leq 6 \%$ - relevo plano a suave ondulado; (b) $6 \%$ $<d \leq 12 \%$ - relevo suave ondulado a moderadamente ondulado; (c) $12 \%<d \leq$ $20 \%$ - relevo moderadamente ondulado a ondulado; (d) $20 \%<d \leq 30 \%-$ relevo ondulado a forte ondulado; (d) Acima de 30\% - relevo forte ondulado, montanhoso e escarpado.

Para a elaboração da carta de Aptidão Agrícola das Terras da Bacia do Rio Pequeno, elaborou-se uma matriz, que se encontra apresentada na Tabela 2. Levou-se em consideração os fatores limitantes ao uso agrícola e as possíveis viabilidades de melhoramento destas condições.

TABELA 2 - MATRIZ PARA A DETERMINAÇÃO DA APTIDÃO AGRÍCOLA DA BACIA DO RIO PEQUENO.

\begin{tabular}{|c|c|c|c|c|c|}
\hline \multirow{2}{*}{ Tipos de Solos } & \multicolumn{5}{|c|}{ 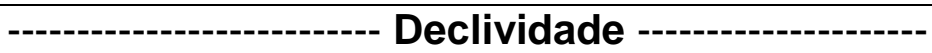 } \\
\hline & $\begin{array}{c}0<d \leq \\
6 \%\end{array}$ & $\begin{array}{l}6<d \leq \\
12 \%\end{array}$ & $\begin{array}{l}12<d \leq \\
20 \%\end{array}$ & $\begin{array}{l}20<d \leq \\
30 \%\end{array}$ & $\begin{array}{l}d> \\
30 \%\end{array}$ \\
\hline C - Cambissolo & $2(a b) c$ & $2(a b) c$ & $3(a b c)$ & $4 \mathrm{P}$ & 6 \\
\hline $\begin{array}{l}\text { LVA - Latossolo Vermelho- } \\
\text { amarelo }\end{array}$ & $1(\mathrm{a}) \mathrm{Bc}$ & $1(\mathrm{a}) \mathrm{bC}$ & 2(a)bc & $3(\mathrm{abc})$ & 6 \\
\hline L - Neossolo Litólico & 6 & 6 & 6 & 6 & 6 \\
\hline $\begin{array}{l}\text { PVA - Argissolo Vermelho- } \\
\text { amarelo }\end{array}$ & $1 \mathrm{aBC}$ & 2abc & $3(a b c)$ & $5 s$ & 6 \\
\hline \multicolumn{6}{|c|}{$\begin{array}{l}\text { *1aBC - Terras pertencentes à classe de aptidão regular para lavouras no nível de manejo A e boa nos níveis B e C; } \\
\text { 1(a)bC- Terras pertencentes à classe de aptidão restrita para lavouras no nível de manejo A, regular no nível B e boa no } \\
\text { C; } \\
\text { 2abc - Terras pertencentes à classe de aptidão regular para lavouras nos níveis de manejo A, B e C; } \\
\text { 2(ab)c- Terras pertencentes à classe de aptidão restrita para lavouras nos níveis de manejo A e B, e regular no nível C; } \\
\text { 2(a)bc - Terras pertencentes à classe de aptidão restrita para lavouras no nível de manejo A e regular nos níveis B e C; } \\
\text { 3(abc) - Terras pertencentes à classe de aptidão restrita para lavouras nos níveis de manejo A, B e C; } \\
\text { 4P - Terras pertencentes à classe de aptidão boa para pastagem plantada; } \\
\text { 5s - Terras pertencentes à classe de aptidão regular para silvicultura; } \\
\text { 6- Terras sem aptidão para o uso agrícola. }\end{array}$} \\
\hline
\end{tabular}


A partir do tratamento prévio das camadas de informações geográficas contendo os dados topográficos de altimetria, declividade, rede de drenagem, corpos d'água e divisores topográficos da bacia hidrográfica, efetuou-se 0 mapeamento das áreas protegidas (APPS), com a utilização de SIG, obtendose, após o processamento dos dados, o Modelo Digital do Terreno (MDT). Com a rede de drenagem servindo de base, foram gerados mapas de distância, em metros, com valor zero, partindo da linha vetorial de drenagem e dos pontos correspondentes às nascentes, inseridos no ponto inicial de cada vertente. Com a utilização da grade MDT foram geradas grades de declividade, da qual foram extraídas classes de APPs.

Para a obtenção do mapa de APPs de margens de rios utilizou-se o mapa de distâncias da rede de drenagem, com faixas de distâncias de 50 metros (buffer), em ambos os lados da drenagem, quando o rio apresentou largura superior a 50 metros. O mapeamento das APPs de nascente foi obtido de forma semelhante ao mapeamento das APPs de margens de rios, porém utilizando-se como dado de entrada um plano de informação contendo somente os pontos correspondentes às nascentes (DIAS et al. 2005).

A carta de conflito do uso atual da bacia do Rio Pequeno foi gerada a partir das seguintes classes de mapeamento, dispostas nas Tabelas 3 e 4.

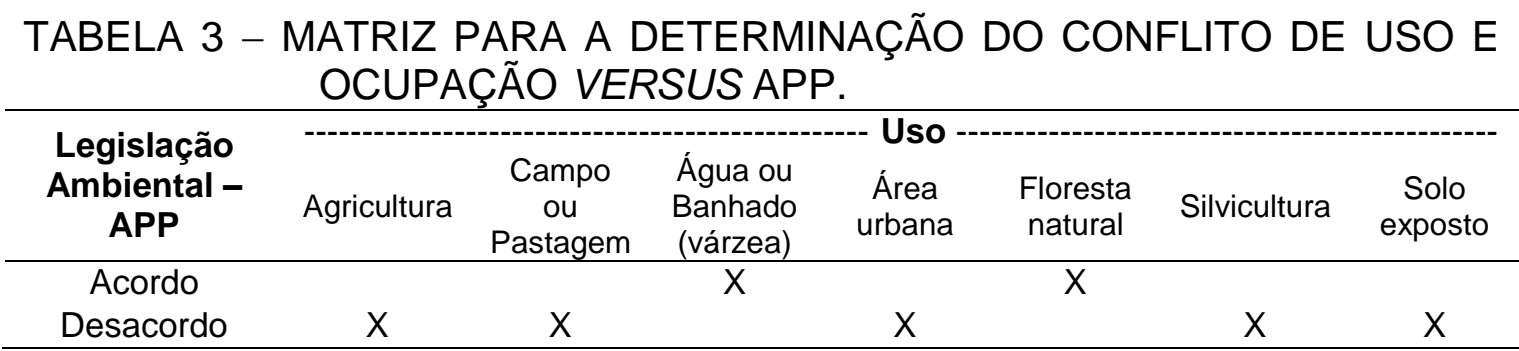


TABELA 4 - MATRIZ PARA A DETERMINACCÃO DO CONFLITO DE USO E OCUPAÇÃO VERSUS APTIDÃO AGRÍCOLA DAS TERRAS DA BACIA DO RIO PEQUENO.

\begin{tabular}{lcccc}
\hline \multicolumn{1}{c}{ Usos } & Agricultura & Pastagem & Silvicultura & Preservação \\
\hline Agricultura & Acordo & Desacordo & Desacordo & Desacordo \\
Campo ou Pastagem & Aceitável & Acordo & Desacordo & Desacordo \\
Floresta natural & Aceitável & Aceitável & Aceitável & Acordo \\
Reflorestamento & Aceitável & Aceitável & Acordo & Desacordo \\
Área urbana & Desacordo & Desacordo & Desacordo & Desacordo \\
Solo exposto & Desacordo & Desacordo & Desacordo & Desacordo \\
Água ou Banhado (várzea) & Aceitável & Aceitável & Aceitável & Acordo \\
\hline
\end{tabular}

Os resultados desta classificação foram decorrentes do cruzamento entre as classes de uso do solo, em confronto com as classes de APPs e aptidão agrícola das terras por meio da operação booleana lógica do tipo $\mathrm{A}$ and B (A - acordo e desacordo quando do confronto com APP; B - acordo, desacordo e aceitável quando do confronto com aptidão agrícola).

Análises empregando árvores de probabilidade também foram realizadas fazendo a associação entre Aptidão agrícola com APP e Uso e ocupação do solo. O levantamento dos percentuais de ocorrência de cada associação foi realizado fazendo-se o cruzamento dos planos de informação, utilizando-se o software SPRING - ferramenta LEGAL. As árvores de probabilidade da natureza e interessado, da associação mencionada acima, foram construídas e calculadas com o auxílio de uma planilha eletrônica, seguindo as recomendações de Caixeta-Filho (2001).

\section{RESULTADOS E DISCUSSÃO}

No presente trabalho verificou-se que $27 \%$ da área total da bacia do rio Pequeno deve ser APP (Figura 1). O resultado do confronto entre o uso atual e a legislação (Figura 2), mostrou que 59\% da área de APP está sendo utilizada de acordo com a legislação. Entretanto, $41 \%$ da área refletiu uso inadequado em relação à APP, o qual se deve principalmente a utilização de zona ripária para outros fins que não a preservação, sendo necessária a sua recuperação (BRISKI et al., 2004). 


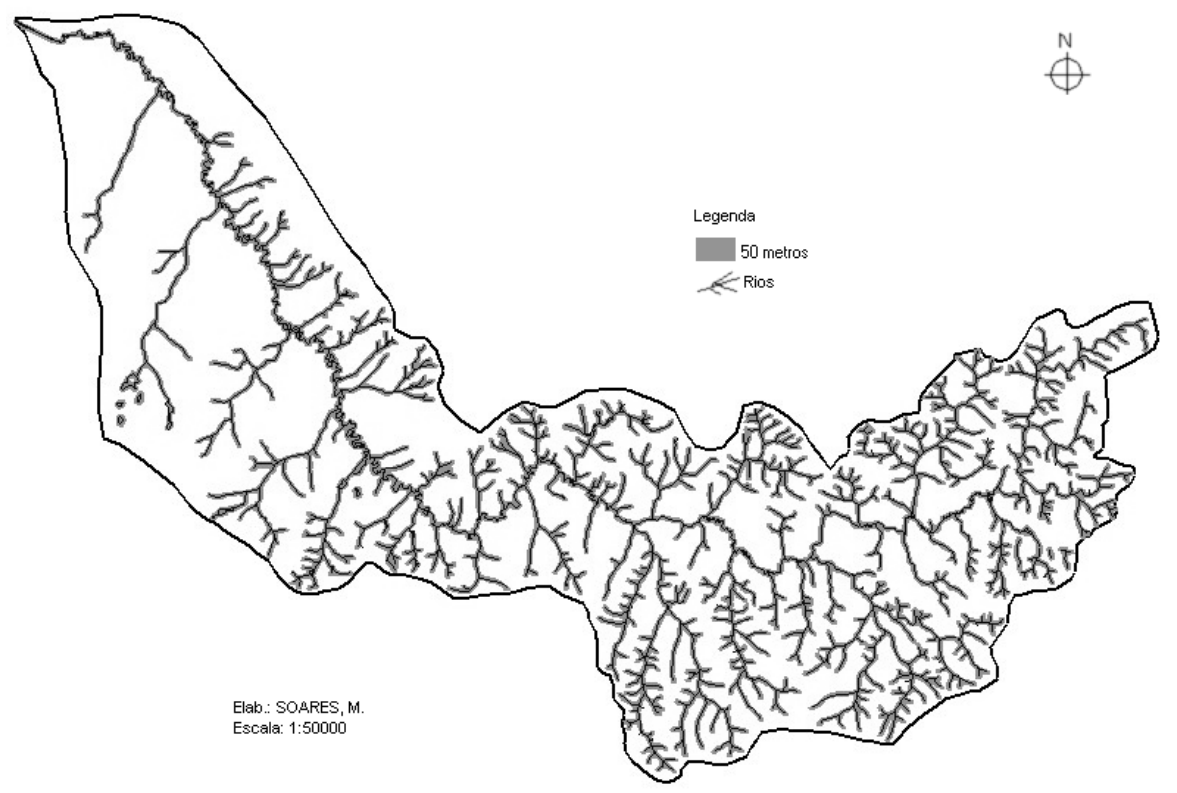

FIGURA 1 - CARTA LEGISLAÇÃO AMBIENTAL (APP) DA BACIA DO RIO PEQUENO.

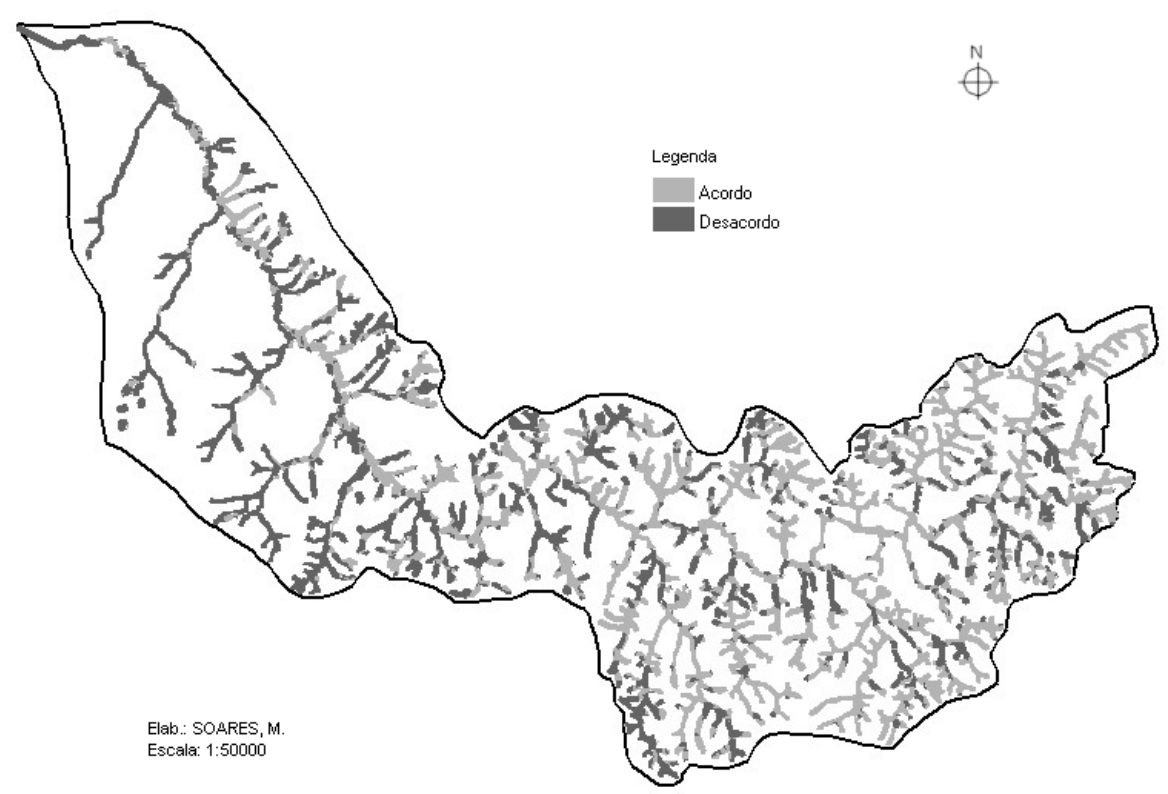

FIGURA 2 - CARTA DE CONFLITO ENTRE USO E OCUPAÇÃO DO SOLO VERSUS LEGISLAÇÃO (APP) DA BACIA DO RIO PEQUENO.

A bacia do rio Pequeno apresentou alto percentual de Organossolos (32\%), indicando inadequação à ocupação urbana e outras modalidades de 
uso rural ou implementação de pólos industriais, o que caracteriza estas áreas como inaptas ao uso agrícola, sendo pertencente à classe 6 (preservação).

Aproximadamente $59 \%$ da área da bacia possui aptidão para agricultura, sendo representada pelas classes 1aBC, 1(a)bC, 2abc, 2(ab)c, 2(a)bc e 3(abc) (Figura 3); 3\% é apta para pastagem plantada, classe 4P; e, 2\% tem aptidão regular para silvicultura, classe $5 \mathrm{~s} ; 36 \%$ da área foi classificada pelo sistema como inapta para o uso agrícola (classe 6), sendo áreas recomendáveis para a preservação da fauna e da flora (RAMALHO FILHO; BEEK, 1994). A preservação abrangeu áreas de Organossolos, Neossolos Litólicos e áreas contendo declividades acima de $30 \%$.

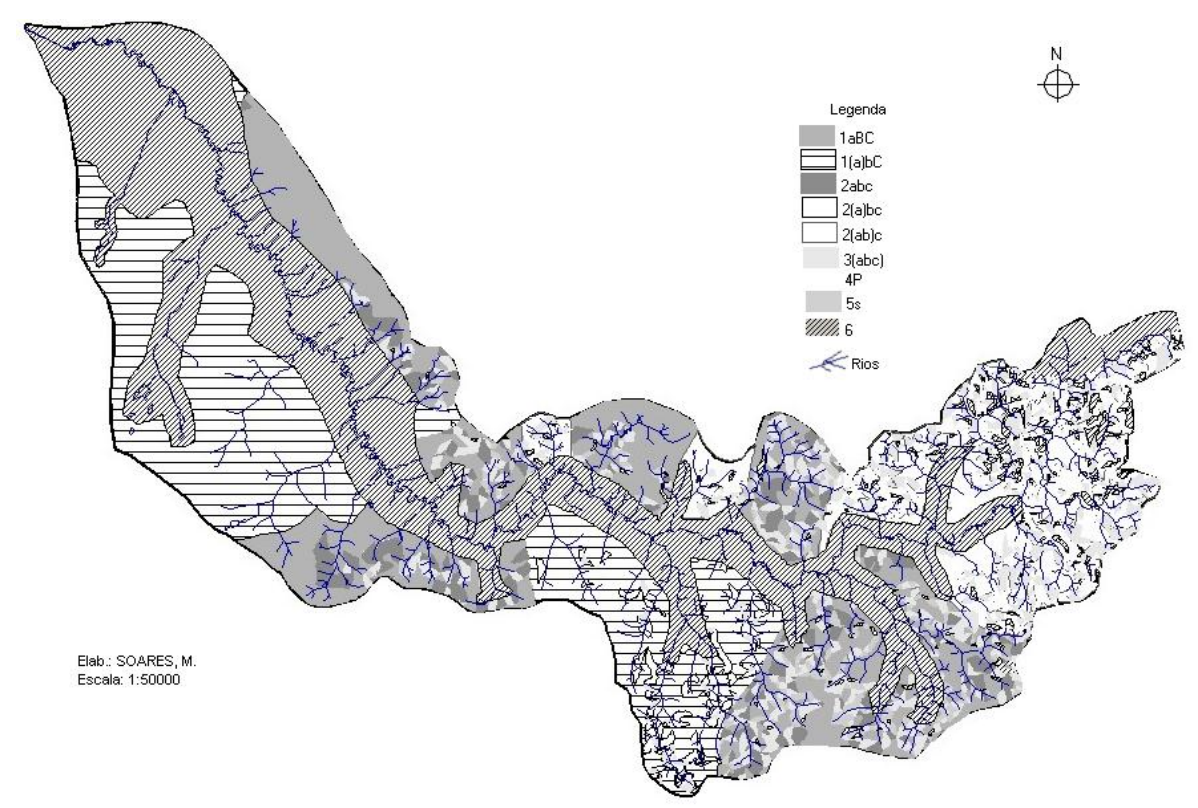

FIGURA 3 - CARTA DE APTIDÃO AGRÍCOLA DA BACIA DO RIO PEQUENO.

Segundo Rostagno (1999), o relevo acentuado é responsável pela ocorrência de erosão, devido à maior intensidade do escorrimento superficial. A utilização de pastagem proporciona o recobrimento da superfície do solo, o que promove a redução da velocidade do escorrimento superficial e, consequentemente, da erosão (PINTO et al., 2005).

A partir das declividades existentes na bacia do rio Pequeno, verificou-se que $68 \%$ da área apresenta relevo que permite a realização de cultivos agrícolas mecanizados. Apenas em algumas áreas com declividades mais 
abruptas, em sua maioria acima de $8 \%$ de declividade, que representam apenas $14 \%$ da área total da bacia, não é possível à utilização de maquinários agrícolas. Dessa forma, em áreas com declividade entre $12 \%$ e $20 \%$, são necessárias práticas de conservação mais complexas para o uso das terras (ROSTAGNO, 1999). No entanto, considerando toda a área da bacia hidrográfica, verificou-se que apenas $16 \%$ está sendo utilizada com atividade agrícola.

Verificou-se que as áreas classificadas inicialmente pelo sistema com potencial para agricultura, pastagem e silvicultura, ficaram reduzidas consideravelmente, devido à inclusão das APPs para $27 \%$ do total da área. Esta área ficou enquadrada como classe 6 (sem aptidão ou preservação).

Com a inclusão de toda a APP, verificou-se que a área classificada inicialmente com aptidão para Agricultura foi reduzida de $59 \%$ para $45 \%$. As áreas com aptidão inicial para Pastagem e Silvicultura foram reduzidas de $3 \%$ para $2 \%$ e de $2 \%$ para $1 \%$, respectivamente. Assim, a "classe preservação" da aptidão agrícola inicial passou de $36 \%$ para $52 \%$ da área total.

Quanto ao resultado do confronto real da área de estudo, que consiste no resultado do conflito entre as classes de Aptidão Agrícola das Terras, APP e uso atual do solo, a análise indicou que $32 \%$ do total da área está sendo utilizada de forma correta, 35\% em desacordo, ou seja, super utilizada, e 33\% está sendo utilizada de forma aceitável, ou sub utilizada (Figura 4). O mesmo foi observado por Rodrigues (1998), Lobo (2002) e Chaves (2005), que avaliando a adequação do uso e ocupação do solo, no que diz respeito à aptidão agrícola das terras em regiões de microbacias no Estado do Distrito Federal, observaram que a maioria das áreas não obedece à potencialidade de uso, resultando na ocorrência de desequilíbrios ambientais e conseqüente degradação dos recursos naturais. 


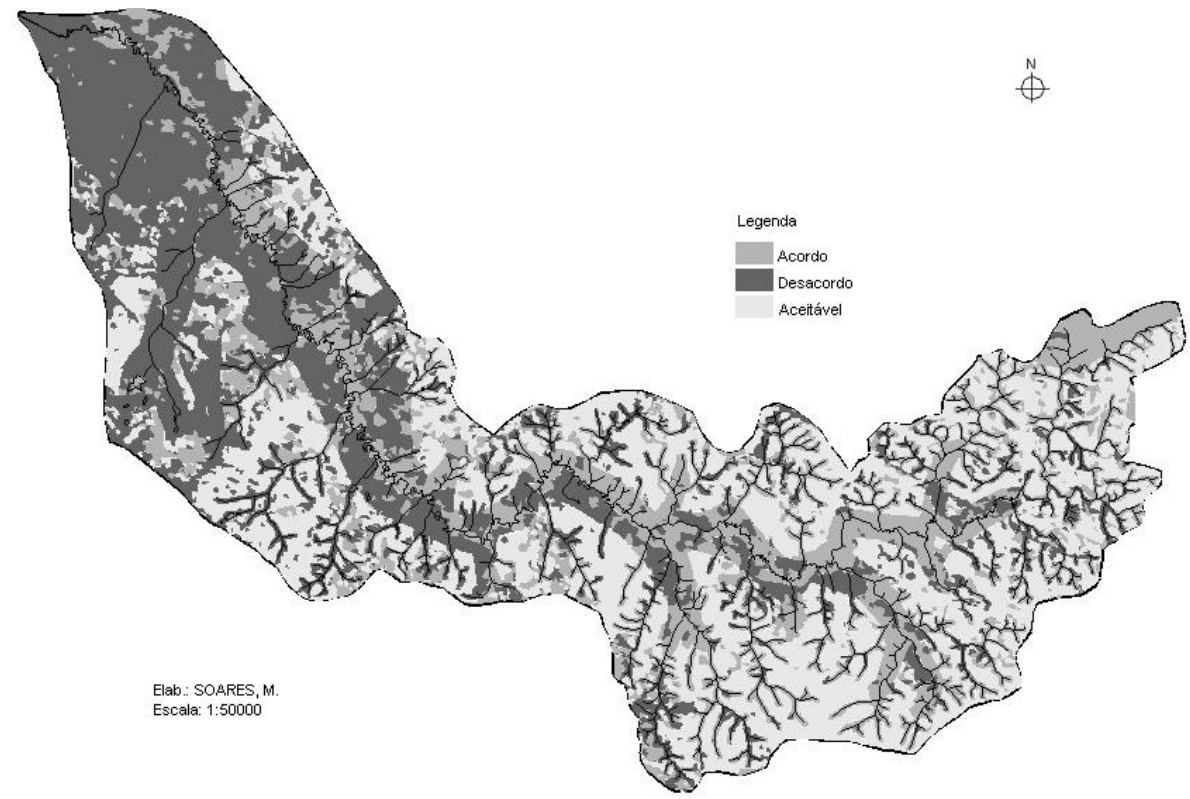

Figura 4 - Carta de Confronto Real da bacia do rio Pequeno.

Notou-se que a consideração da legislação ambiental fez com que a classe Acordo aumentasse de $24 \%$ para $32 \%$, enquanto que a classe Aceitável (sub utilizado) reduzisse de $47 \%$ para $33 \%$. Este fato é explicado por boa parte da área de estudo (43\%) estar ocupada com vegetação, concentrando-se principalmente nas áreas de APPs, ou seja, onde a legislação ambiental determina a preservação (RAMALHO FILHO; BEEK, 1994).

Ao se realizar o confronto direto da Legislação Ambiental com o sistema de Aptidão Agrícola das Terras, fica evidente que a classe de desacordo aumenta consideravelmente, pois o sistema em si não considera a legislação. Os resultados mostram que, para o planejamento ambiental, é necessário incluir ou sobrepor na elaboração das cartas de zoneamento as áreas protegidas por lei.

A partir da árvore de probabilidade da natureza (Figura 5) verificou-se que a maior parte da área da bacia do rio Pequeno, determinada pelo sistema de aptidão agrícola como apta para a agricultura $(44,67 \%)$, está sendo utilizada para Florestas e Áreas seminaturais (40,90\%). Em seguida, ocorrem os usos Campo ou pastagem, Agricultura e Áreas urbanas, ocupando 18,72\%, 15,72\%, e $11,14 \%$ desta porção, respectivamente. $A$ área de silvicultura também teve boa representação, ocupando $6,21 \%$ da área apta para a Agricultura (Ac). As 
áreas possuindo aptidão para Pastagem (1,85\%) e Silvicultura $(0,89 \%)$, também possuem a maior ocupação com vegetação natural, com $80,53 \%$ e $81,22 \%$ do total de cada classe, respectivamente. As áreas sem aptidão agrícola, grande parte delas em função do organossolo e legislação ambiental, somaram 52,59\%. Deste total, a interseção entre Preservação (Ps) e Vegetação natural (Fs) ocorreu em $22,99 \%$ da área total da bacia do rio Pequeno. Embora seja uma parcela significativa, os usos inadequados (Agricultura, Campo ou pastagem, Silvicultura, Solo exposto e Urbanização) somaram a maior parcela, ou seja, $27,34 \%$ do total da área da bacia. Logo, de forma geral, verifica-se que a área da bacia possui tendência de uso inadequado, o qual reflete de forma direta na quantidade e qualidade da água da bacia hidrográfica (PINTO et al., 2005).

A partir da árvore de probabilidade do interessado (Figura 6), verificouse que $52,89 \%$ da área total destinada à Preservação (Ps), seguindo as recomendações da legislação, estão condicionadas à presença de Vegetação (Fs). As áreas de Agricultura ( $\mathrm{Ag}$ ) Campo ou Pastagem ( $\mathrm{Cp}$ ) e Solo Exposto (Se) encontram-se divididas entre áreas de proteção e uso permitido do solo. Este fato merece maior atenção por parte dos administradores e gestores ambientais, para as questões de planejamento, pois o desacordo ocorreu em $7,63 \%, 7,42 \%$ e 2,34\% da área total da bacia, para uso e ocupação Agricultura (Ag), Campo ou Pastagem (Cp) e Solo Exposto (Se), respectivamente. Nas áreas contendo solo exposto, verificou-se também probabilidade das mesmas serem aptas para a agricultura $(\mathrm{P}(\mathrm{Ac} \square \mathrm{Se})=47,89 \%)$. Este fato confirma a hipótese de que grande parte das áreas contabilizadas como Solo Exposto (Se) realmente estavam sendo preparadas para o cultivo, no momento da coleta das informações (imagens de satélite) utilizadas no presente trabalho. 


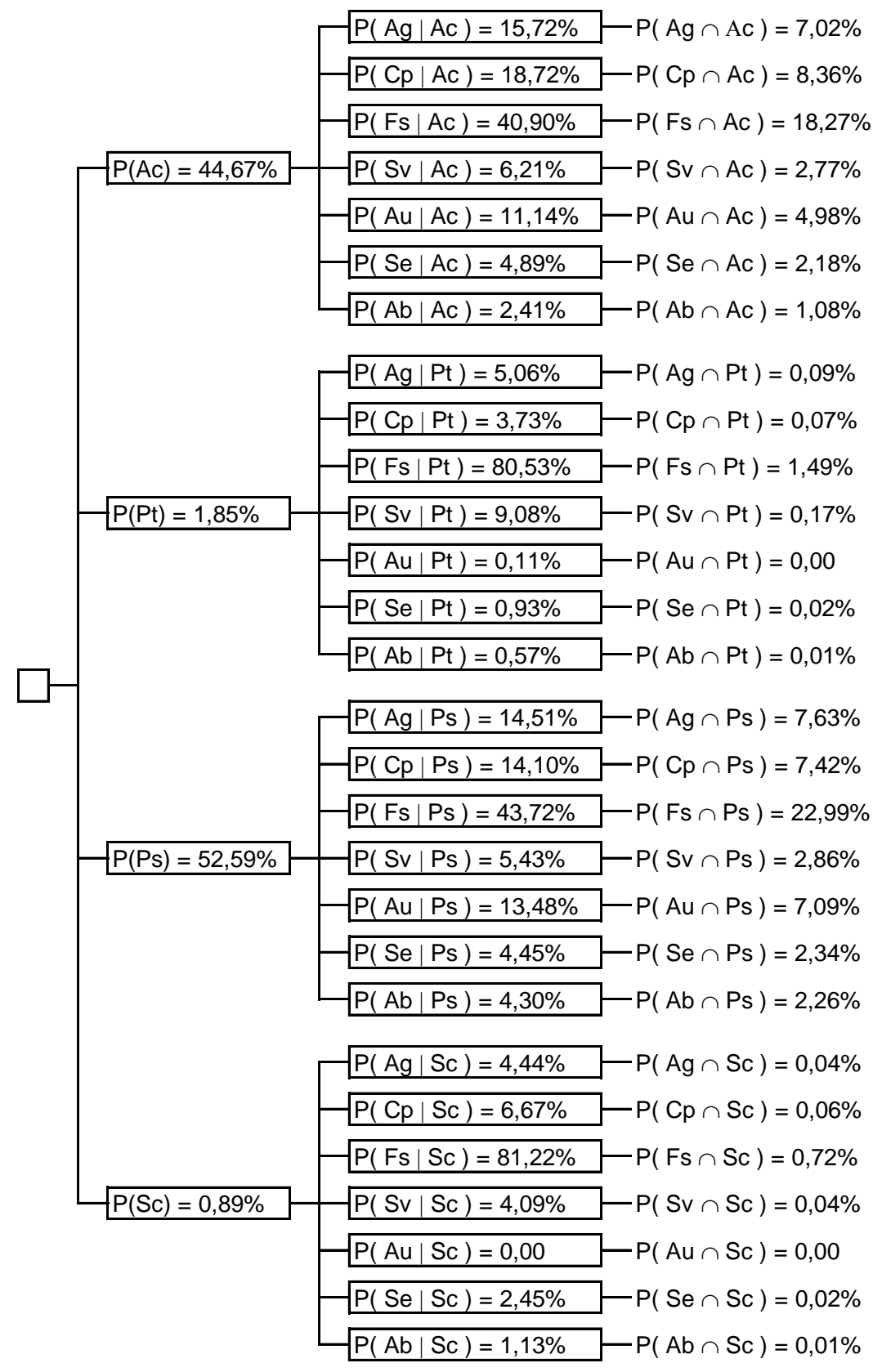

\section{Legenda:}

Aptidão agrícola: Ac - Agricultura; Pt - Pastagem; Ps - Preservação; Sc - Silvicultura

Classes de uso e ocupação: Ag - Agricultura; $\mathrm{Cp}$ - Campo ou pastagem; Fs - Florestas ou Áreas seminaturais; Sv - Silvicultura; Au - Áreas urbanas; Se - Solo exposto; Ab-Água ou banhado (várzea)

FIGURA 5 - ÁRVORE DE PROBABILIDADE DA NATUREZA ESTRUTURADA A PARTIR DOS DADOS OBTIDOS COM O MAPA DE APTIDÃO AGRÍCOLA (CONSIDERANDO A LEGISLAÇÃO) E USO E COBERTURA DO SOLO. 


$$
\begin{array}{ll}
\hline \mathrm{P}(\mathrm{Ac} \mid \mathrm{Ag})=47,49 \%-\mathrm{P}(\mathrm{Ac} \cap \mathrm{Ag})=7,02 \% \\
\hline \mathrm{P}(\mathrm{Pt} \mid \mathrm{Ag})=0,63 \%
\end{array}
$$

Legenda:

Aptidão agrícola: Ac - Agricultura; Pt - Pastagem; Ps - Preservação; Sc - Silvicultura

Classes de uso e ocupação: Ag - Agricultura; $\mathrm{Cp}$ - Campo ou pastagem; Fs - Florestas ou Áreas seminaturais; Sv - Silvicultura; Au - Áreas urbanas; Se - Solo exposto; Ab - Água ou banhado (várzea)

FIGURA 6 - ÁRVORE DE PROBABILIDADE DO INTERESSADO ESTRUTURADA A PARTIR DOS DADOS OBTIDOS COM O MAPA DE APTIDÃO AGRÍCOLA (CONSIDERANDO A LEGISLAÇÃO) E USO E COBERTURA DO SOLO. 


\section{CONCLUSÕES}

As análises do potencial de uso das terras em conjunto com a legislação ambiental representaram importantes instrumentos de subsídios ao planejamento ambiental, sendo que as metodologias se complementam na identificação de áreas frágeis e limitantes, bem como de áreas com alto potencial agrícola, auxiliando na elaboração de planos de manejo em áreas naturais ou unidades de conservação.

A bacia possui tendência de utilização inadequada. A maioria da ocupação com urbanização e atividades agrícolas ocorreu em organossolos, solos de alta fragilidade ambiental e baixo potencial agrícola por ser pouco desenvolvido, mal drenado, entre outras características.

Embora a presença da vegetação natural seja notável em toda a bacia do rio Pequeno, a sua redução ao longo do tempo é um fato preocupante, o que expõe os solos aos fatores de degradação ambiental.

\section{REFERÊNCIAS}

ANDREOLI, C.V.; DALARMI, O.; LARA, A.I.; ANDREOLI, F.N. Mananciais de Abastecimento do Sistema Integrado da Região Metropolitana de Curitiba RMC. In. SIMPÓSIO BRASILEIRO DE ENGENHARIA SANITÁRIA E AMBIENTAL, 9., 2000, Porto Seguro, BA. Anais... Porto Seguro, BA, 2000. p. 196-205.

BRASIL. Resolução CONAMA no 302, de 20 de março de 2002. Dispõe sobre os parâmetros, definições e limites de Áreas de Preservação Permanente de reservatórios artificiais e o regime de uso do entorno (2002a).

BRASIL. Resolução CONAMA no 303, de 20 de março de 2002. Dispõe sobre parâmetros, definições e limites de Áreas de Preservação Permanente (2002b).

BRISKI, S.J.; SALAMUNI, E.; SANTOS, L.J.C.; MANTOVANI, L.E. Geotecnologias aplicadas ao planejamento e gestão de bacias hidrográficas de mananciais. Ciência e Natura, Santa Maria, v. 26 p. 429-444, 2004.

CAIXETA-FILHO, J.V. Pesquisa operacional: técnicas de otimização aplicadas a sistemas agroindustriais. São Paulo: Atlas, 2001. 171p. 
CHAVES , A.A.A. Avaliação do uso e qualidade do solo e da água da região de nascentes do Rio Descoberto, DF. 2005. 92 f. Dissertação (Mestrado em Ciências Agrárias) - Faculdade de Agronomia e Medicina Veterinária, Universidade de Brasília, Brasília, 2005.

CHUEH, A.M. Análise do uso do solo e degradação ambiental na bacia hidrográfica do rio Pequeno - São José dos Pinhais/PR, por meio do diagnóstico físico-conservacionista - DFC. 2004. 102 f. Dissertação (Mestrado em Geografia). Universidade Federal do Paraná, Curitiba, 2004.

COMEC - Coordenadoria da Região Metropolitana de Curitiba, Estado do Paraná. Cartas planialtimétricas, 1:10.000, 1976.

DIAS, N.W.; BATISTA, G.T.; TARGA, M.S.; CATELANI, C.S.; MONTESI, E.C. Estudo da adequabilidade de uso do solo e viabilidade econômico-ambiental: o caso da fazenda Camburi. Repositório Eletrônico do Departamento de Ciências Agrárias da UNITAU, 59: p. 1-39. 2005. Disponível em: $<$ http://www.agro.unitau.br:8080/dspace/bitstream/2315/59/1/Adequa Camburi. pdf> Acesso em: 02 dez. 2009.

DONHA, A.G.; SOUZA, L.C.P.; SUGAMOSTO, M.L. Determinação da fragilidade ambiental utilizando técnicas de suporte à decisão e SIG. Revista brasileira de engenharia agrícola e ambiental, Campina Grande, v. 10, n. 1, p. 175-181, 2006.

EMBRAPA. Empresa Brasileira de Pesquisa Agropecuária. Serviço Nacional de Levantamento e Conservação de Solos (Rio de Janeiro - RJ). Levantamento de reconhecimento dos solos do estado do Paraná. Londrina: IAPAR, 2v, 1984. 788p.

EMBRAPA. Centro Nacional de Pesquisa de Solos (Rio de Janeiro - RJ). Sistema Brasileiro de Classificação de Solos. 1. ed. Brasília: Embrapa Produção de Informação; Rio de Janeiro: Embrapa Solos, 1999. 412p.

FIORIO, P.R.; DEMATTÊ, J.A.M.; MELÉM JÚNIOR, N.J.; MAZZA, J.A. Potencialidade do uso da terra na microbacia hidrográfica do córrego do Ceveiro na região de Piracicaba. Scientia Agrícola, Piracicaba, v. 56, n. 4, p. 1273-1280, 1999. Suplemento.

IBGE - Instituto Brasileiro de Geografia e Estatística. Manual Técnico da Vegetação Brasileira. Rio de Janeiro, 1992. 92p.

LOBO, G.A.S. Aplicação de geotecnologias no planejamento de uso áreas rurais. 2002. 144 f. Dissertação (Mestrado em Ciências Agrárias) - Faculdade de Agronomia e Medicina Veterinária, Universidade de Brasília, Brasília, 2002.

PINTO, L.V.A.; FERREIRA, E.; BOTELHO S.A.; DAVIDE, A.C. Caracterização física da bacia hidrográfica do Ribeirão Santa Cruz, Lavras, MG e uso conflitante da terra em suas áreas de preservação permanente. Revista Cerne, Lavras, v. 11, n. 1, p. 49-60, 2005.

RAMALHO FILHO, A.; BEEK, K. J. Sistema de avaliação da aptidão agrícola das terras. $3^{\mathrm{a}}$ ed. Rio de Janeiro: EMBRAPA-CNPS, 1994. 65p. 
RODRIGUES, L.M.R. Geoprocessamento aplicado ao estudo da evolução e adequação do uso agrícola das terras na microbacia do Córrego Lamarão, DF. 1998. 109 f. Dissertação (Mestrado em Geologia). Instituto de Geociências da Universidade de Brasília, Brasília, 1998.

ROSTAGNO, L.S.C. Caracterização de uma paisagem na área de influência do reservatório da usina hidrelétrica do Funil, ljaci-MG. 1999. 66 f. Dissertação (Mestrado em Agronomia: Solos e Nutrição de Plantas). Universidade Federal de Lavras, Lavras, 1999.

SOARES, M.R.G.J.; MELLEK, J.E.; ORRUTÉA, A.G.; KUMMER, L.; NUNES, T.; BARROS, Y.J.; ANDRETTA, R.; FAVARETTO, N.; SOUZA, L.C.P. Potencial de uso agrícola e fragilidade ambiental da microbacia do rio Campestre, Colombo - PR . Scientia Agraria, Curitiba, v. 9, n. 4, p. 587-596, 2008.

WEBER, E.; DUARTE, G.F.; FRANK, M.; HOFF, R; ZORNER, S.; BASSANI, E.; JUNQUEIRA, I. Estruturação de sistemas de informação ambiental em bacias hidrográficas: o caso da bacia hidrográfica do rio Caí - RS. In: GIS BRASIL, CONGRESSO E FEIRA PARA USUÁRIOS DE GEOPROCESSAMENTO, 6., 1998, Curitiba, PR. Anais... Curitiba, PR, 1998. 